Check for updates

London, UK

fran.robinson8@gmail.com

Cite this as: BMJ 2021;372:n58

http://dx.doi.org/10.1136/bmj.n58

Published: 18 January 2021

\section{Empowering patients through technology: GP Amir Hannan}

\section{GP Amir Hannan talks to Francesca Robinson about providing his patients with reliable information during the pandemic and encouraging them to access their electronic health records}

\section{Francesca Robinson}

Amir Hannan's ethos is to educate patients and empower them to use the information in their health records and the supporting advice his practice provides.

The mission statement of his practice, the Haughton Thornley Medical Centres in Greater Manchester, is: "There for you all your life, your good health with our support, empowering you to live well.” Hannan pioneered giving patients access to their full medical records, including what doctors or nurses have written about them, over 16 years ago.

As the covid-19 virus took hold last year, Hannan prepared by contacting any patients who had not yet signed up for online services to explain why it was important to do so. Currently three quarters of his practice population, 10 ooo patients, can access their records online.

"You've got to engage and educate people and give them the best information you can to enable them to make informed decisions about their healthcare through a shared decision making process. That's always been the reason for everything I do," explains Hannan.

The practice website has been designed to support and enhance patient care. It has over 700 pages of healthcare information, video clips, and links to further sources of material. It also includes regularly updated information and advice about covid-19.

During a consultation, patients can be directed to specific webpages or to local services. They can also $\log$ in to their records to find out the results of tests or scans and to revisit what they discussed with their doctor. "Now, when I turn my computer screen around so my clinical system can be seen both by the patient and me, we move into an exciting space where we can share the information I have," Hannan says.

"The key to unlocking healthcare is both the GP electronic health record and the consultation-this is where what I call the 'partnership of trust' is formed. I encourage the patient to tell me as much as they can about their health and in return they can expect me to help them get the best medicine possible."

Hannan's area has been hit hard by covid-19 and he says people have been scared and confused. With the ever changing situation, his patients have appreciated having up to date information they can trust from their practice. "The feedback I have had from patients has been off the scale," Hannan says.

In addition to working nine sessions a week in the practice, Hannan also holds leadership roles as co-chair of the Greater Manchester NHS Values Group, chair of the West Pennine Local Medical Committees (LMCs), chair of the Association of Greater Manchester LMCs, and chairman of the World Health Innovation Summit. He sees his most important role, however, to patients and staff to understand what their concerns are. This gives me a finger on the pulse," he says.

"I want to support the local population-to me that's the beauty of general practice. It's the relationship that I have with my patients that makes me want to come to work every day."

\section{Nominated by Tessa Richards}

"When I look at what Amir is doing for his patients, which includes still seeing them face to face and doing home visits, I am inspired and humbled.

"The practice's website is a mine of information, with each link providing access to further information and video clips. Some of the latter are nothing short of inspiring. There is a lovely one of Amir doing a home visit with a patient who had been hospitalised for a hip fracture and, when the hospital said, 'We can't find your notes,' she said, 'No problem-I have them on my phone."”

Tessa Richards is a senior editor at The BMJ

You can visit the Haughton Thornley Medical Centres' website at www.htmc.co.uk

To nominate someone who has been a role model during your medical career, send their name, job title, and the reason for your nomination to arimmer@bmj.com as being a GP in the community. "I'm always listening 